\title{
Low Density Linear Polyethylene Reinforced with Alkali and MAPE Treated Fibers from Coffee Pulp
}

\author{
Ahmat Tom1, Abel Tame², Paul Nestor Djomou Djonga ${ }^{3 *}$, Bakary Tigana Djonse Justin ${ }^{3,4}$, \\ Eugenie Géraldine Nga Abena ${ }^{5}$
}

${ }^{1}$ Department of Energy Engineering, University Institute of Technology, University of Ngaoundere, Ngaoundere, Cameroon

${ }^{2}$ Department of Chemistry, Faculty of Science, University of Yaoundé I, Yaoundé, Cameroon

${ }^{3}$ Department of Textile and Leather Engineering, National Advanced School of Engineering of Maroua, Maroua Cameroon

${ }^{4}$ Department of Chemistry, Faculty of Science, University of Maroua, Maroua, Cameroon

${ }^{5}$ Department of Physics, Faculty of Science, University of Yaoundé I, Yaoundé, Cameroon

Email: ahmattom@yahoo.fr, *djomoupaul@gmail.com

How to cite this paper: Tom, A., Tame, A., Djonga, P.N.D., Justin, B.T.D. and Abena, E.G.N. (2021) Low Density Linear Polyethylene Reinforced with Alkali and MAPE Treated Fibers from Coffee Pulp. Open Journal of Composite Materials, 11, 94-110. https://doi.org/10.4236/ojcm.2021.114008

Received: June 16, 2021

Accepted: October 25, 2021

Published: October 28, 2021

Copyright $\odot 2021$ by author(s) and Scientific Research Publishing Inc. This work is licensed under the Creative Commons Attribution International License (CC BY 4.0).

http://creativecommons.org/licenses/by/4.0/

\section{(c) (i) Open Access}

\begin{abstract}
In this work fibers derived from coffee, hulls have been incorporated into Linear Low Density Polyethylene (LLDPE). The influence of the filler content on the thermal and physicomechanical properties of the composites obtained was assessed. The results showed that the incorporation of fibers was able to improve the thermostability of LLDPE/Coffee hulls fibers; comparing the treated fiber composite with untreated fiber composites, the chemical treatment reduces by $58.3 \%$ the water absorption, while increasing the elongation and tensile strength by about $48 \%$ and $17 \%$ respectively. Moreover, due to better interfacial interaction induced by MAPE, the corresponding composite exhibited better properties compared to the untreated fiber composite. Results are indicative of the fact that both mercerization and MAPE (coupling agent) have significant positive effects on the fiber-matrix interaction in terms of adhesion, wetting and dispersion, this treatment produced a better fiber distribution and consequently a more uniform composite morphology without voids and gaps between the fibers and the matrix, allowing the possibility to use higher fiber contents (up to $30 \%$ wt.) with acceptable mechanical properties.
\end{abstract}

\section{Keywords}

Fiber from Coffee Fiber Hull, Linear Low Density Polyethylene, Composite, MAPE 


\section{Introduction}

A strong increase in environmental concerns has arisen in the last years. This fact, together with the continuous increase in petroleum prices and the overall depletion of fossil fuels has encouraged researchers to develop new environmentally friendly materials [1] [2]. One of the engineering fields that have experienced a more valuable growth is that related to composite materials with natural fillers/reinforcements such as natural fiber reinforced plastics [2] [3]. The use of natural fillers/reinforcements into polymeric matrices could lead to multiple advantages, such as clear cost reduction, lightness and good balance on mechanical properties, and a marked low environmental impact as well, due to their abundance, availability, low density and high specific strength compared to synthetic fibers [4]. For these reasons some technological sectors such as aerospace, automotive, building among others and other sectors, such as packaging, have shown a clear interest in these materials [2] [5] [6] [7]. Despite this, natural fillers/reinforcements are majorly lignocellulosic materials having a number of $-\mathrm{OH}$ groups, and therefore, they show extremely high hydrophilicity. This results in poor interaction between the usually hydrophobic polymer matrix and natural fiber. In addition, the hydrophilic nature of the filler/reinforcement also leads to the aggregate formation (poor particle dispersion), which results in poor material cohesion and, subsequently, decrease mechanical and thermal properties such as tensile strength, flexural strength, and thermal stability [8] [9]. Improvement of interface adhesion in natural fiber-reinforced plastic can be achieved by several strategies: on one hand, by lowering the hydrophilicity of the filler/reinforcement and on the other hand, by promoting chemical interactions between the filler/reinforcement and the polymer matrix. To achieve this objective several approaches can be used, such as selective surface modification of fillers, modification of the polymer matrix by additives and using compatibilizers to provide increased interactions among the polymer-particle interface [2] [10]. This study focuses on the elaboration and characterization (thermal and mechanical properties) of composites consisting of LLDPE (a type of plastic widely used in industrial products and households. Besides, LLDPE also suits filling, reinforcing, and blending [11]) and fibers from coffee pulp (FFC) which were extracted from waste coffee hulls using alkaline treatment method. Waste coffee hulls are abundantly available at the end of each coffee season, it's either burned as waste or used as fertilizer due to its excellent biodegradable properties [12]. This research is aimed at valorizing this waste, by using it to reinforce plastic materials, thereby giving it an added value and increasing farmers' incomes. Farmers will no more grow coffee only for their seed but also for their skin.

\section{Experimental}

\subsection{Materials}

LLDPE granules obtained from the Department of chemical engineering at the Faculty of Science in Laval University of Quebec, with the following properties: 
melting temperature of $122^{\circ} \mathrm{C}$, density of $0.916 \mathrm{~g} \cdot \mathrm{cm}^{-3}$ and melt-flow index of 40 $\mathrm{g} /(10 \mathrm{~min})$ at $230^{\circ} \mathrm{C}$ were used.

Coffee hulls were collected from a coffee grinding mill in a rural area of Cameroon (Nkongsamba) and grinded on a Reich brand mill. The fibers were first washed thoroughly with $2 \%$ detergent to remove water soluble ingredient prior to chemical treatment, and dried in an oven at $70^{\circ} \mathrm{C}$ for 24 hours. The dried fibers were designated as untreated fibers. These fibers were then subjected to chemical treatment. Reagent grade chemicals were used for fiber surface modifications, namely, sodium hydroxide $(\mathrm{NaOH})$, ethanol, and acetic acid (Aldrich Chemical Co. Ltd.).

\subsection{Alkaline Treatment}

Untreated fibers were soaked in $\mathrm{NaOH}$ solution (5\%) for 15 min at room temperature under magnetic agitation. The filaments were filtered and washed with hot water after the chemical treatment and were immersed in the distilled water containing $1 \%$ acetic acid to neutralize the excess of $\mathrm{NaOH}$ and the filaments were finally dried for $12 \mathrm{~h}$ at $60^{\circ} \mathrm{C}$ in an oven for any further use.

\subsection{Composite Production}

Coffee fibers hulls with various concentrations $(0,15,30$, and $40 \mathrm{wt} \%)$ were blended with LLDPE matrix in a plastic mixer (Haake Rheocord 9000, Germany) using a rotor speed of $60 \mathrm{rpm}$ at $185^{\circ} \mathrm{C}$ for $8 \mathrm{~min}$. Then, the obtained mixture was compression moulded at $185^{\circ} \mathrm{C}$ for $15 \mathrm{~min}$ under $10 \mathrm{MPa}$. The samples were left at room temperature for 5 days before use.

\subsection{Structural Characterization of Raw Materials}

\subsubsection{FTIR}

The infra-red spectrum was analyzed using the Perkin Elmer Frontier attenuated total reflectance (ATR) apparatus equipped with a Diamond/ZnSe crystal. $2 \mathrm{mg}$ of grounded powder was deposited on the crystal device. Each spectrum was obtained by 32 scans with a resolution of $4 \mathrm{~cm}^{-1}$ from 4000 to 600 $\mathrm{cm}^{-1}$.

\subsubsection{Scanning Electron Microscopy (SEM) Observation}

The morphology evaluation of coffee fibers was analyzed using a JEOL 6490 (JEOL, Japan). The morphology evaluation of FFCs which were extracted from coffee hulls using alkaline treatment method and the interfacial bond between FFCs and LLDPE matrix in prepared composites and the morphological evaluation of LLDPE/FFCs composites before and after biodegradation were performed using a Hitachi S-4800 Scanning Electron Microscope (Hitachi, Japan).

\subsubsection{Gravimetric Thermal Analysis (ATG)}

The thermal gravimetric analysis of coffee hulls was conducted by thermogravimetric (TG-DTG) and differential scanning calorimetry (DSC). 20 to $22 \mathrm{mg}$ of very fine particles of coffee hulls sample were placed in an alumina crucible and 
taken for analysis. The samples were heated up, steadily at a rate of $10^{\circ} \mathrm{C} / \mathrm{min}$ from $24^{\circ} \mathrm{C}$ to $1000^{\circ} \mathrm{C}$ in the ambient air of the laboratory, and an isotherm at $900^{\circ} \mathrm{C}$ for 30 minutes under argon medium. A device of the brand LINSEIS STA-PT 1000 (from physic-chemistry of Mineral Materials Laboratory, Faculty of Science, University of Yaoundé 1-Cameroon) was used for the thermal analysis.

\subsection{Physicochemical Characterization of Coffee Hulls}

The following tests have been carried out:

1) Water and dry matter content

The determination of the water content was carried out by AFNOR method (1982) reported by [13]. A mass of the fresh sample is dried at $105^{\circ} \mathrm{C}$ to constant weight in an oven for 24 hours.

\section{2) Crude fiber content}

The crude fiber content of the samples was determined by Weende method [14]. This method consists of treating the sample at the boiling point with sulfuric acid and then with soda. The residue obtained is dried and then calcined and weighed.

\section{3) Lignin content}

The lignin content was determined by the Klason method reported by [15]. This so-called Klason lignin method uses the property of the insolubility of lignin in a concentrated acidic medium which hydrolyzes and dissolves all other constituents. Its objective is to obtain an essentially woody residue.

\section{4) Cellulose content}

Cellulose is insoluble in ethanol as long as nitric acid converts lignin to alcohol soluble nitro products and hydrolyzes hemicelluloses.

\section{5) Apparent density}

The method described by Ernesto de la Torre Chauvin in 2015 [16] was used to evaluate the apparent density (Equation (1)). The measure of apparent density consists to place an empty volumeter of capacity $1 \mathrm{~m}^{3}$ on the SEDITECH balance with a precision of 1/1000 and tare. Fill the volumeter with coffee hulls until 1 $\mathrm{m}^{3}$. For a volume $V_{i}$ of powder, record the mass $m_{i}$. Determine the value of mean and the standard deviation which represents the density $\rho$ of the micronized coffee hulls powder.

$$
\rho=\frac{m_{i}}{V_{i}}
$$

where $m_{i}=$ mass of the powder and $V_{i}=$ volume of the powder.

\section{6) Wetted density}

The method described by Ernesto de la Torre Chauvin in 2015 [16] was used to evaluate the wetted density. It consists to take an empty flask of volume $V_{o}$ and weight the mass of the flask $\left(m_{o}\right)$. Add a mass $\mathrm{m}_{1}$ of water, and a mass $m_{2}$ of coffee hulls powder in the flask and let stand. Let all the mixture stand avoiding the formation of air bubbles in the flask and note the mass $\left(m_{3}\right)$. The wet density 
$\rho_{w}$ is given by Equation (2). Calculate the average and the standard deviation of the records.

$$
\rho_{w}=\frac{\rho_{\text {water }}\left(m_{2}-m_{o}\right)}{\left(m_{2}-m_{o}\right)-\left(m_{3}-m_{1}\right)}
$$

\subsection{Composites Production}

In order to evaluate the importance of coffee hulls fiber composites, different coffee hulls fiber fractions were used to prepare composites, besides the use of a compatibilization agent (MAPE). The impact of fiber proportion on mechanical properties was assessed. Coffee hulls fiber was blended with LLDPE and maleic anhydride polyethylene as coupling agent. The processing temperature in the extruder was $160^{\circ} \mathrm{C}$ in order to prevent coffee hulls fiber degradation and provide the fusion between the materials. The material was processed in twin screw extruder Werner \& Pfleiderer Krupp model ZSK-25, and chopped a SAGEC Model GS mill 70. The next step was to inject LLDPE and coffee hulls fiber as the specimen in injection Semerano Model 650/247 [17].

\subsection{Physicochemical and Mechanical Characterization of Composite (Coffee Fiber/LLDPE) Water Absorption Test (\%)}

The water absorption tests of pure LLDPE and various LLDP/FFCs composites were carried out following ASTM D 570-99 standard. Rectangular samples were cut with the dimension of $39 \times 10 \times 3 \mathrm{~mm}$, dried at $105^{\circ} \mathrm{C}$ until the weight remained unchanged, cooled to room temperature in a desiccator using silica gel, and immediately weighed with an accuracy of $0.001 \mathrm{~g}$. To investigate the water absorption of LLDPE/FFCs composites, the samples were immersed in distilled water for $24 \mathrm{~h}$ at room temperature. Then, the sample was taken, with the excess water on their surface removed using a soft cloth, and weighed. The percentage of water absorption $(W)$ of the samples was calculated using the following Equation (3):

$$
W(\mathrm{wt} \%)=\frac{W_{2}-W_{1}}{W_{1}} \times 100
$$

$W_{1}$ : weight of the specimen before immersion.

$W_{2}$ : weight of the specimen after immersion.

\subsubsection{Apparent Porosity \%}

During drying and firing, the added particles burn to leave voids due to their breakdown, but also to gas emissions by decomposition of the matter (water, carbon dioxide). Noteworthy, there is no fixed maximal porosity for fired red mud bricks [18].

Apparent porosity expresses, as a percent, the relationship of the volume of open pores of the specimen to its exterior volume. Calculate the apparent porosity as follows Equation (4):

$$
P(\%)=\frac{M-D}{V} \times 100
$$


where $V\left(\mathrm{~cm}^{3}\right)$ is the exterior volume $(V=M-S)$.

$D$ : dried mass, $M$ : saturated mass, $S$ : suspended mass in water.

\subsubsection{Mechanical Test (MPa)}

The tensile and flexural tests of pure LLDPE and LLDPE /FFCs composites were carried out following ASTM D 638 and ASTM D 790 standards, respectively. For the tensile strength test, the specimens were cut with dimensions of $165 \times 19 \times 3$ $\mathrm{mm}$ and crosshead speed was $2 \mathrm{~mm} \cdot \mathrm{min}^{-1}$. For the 4 -point bending flexural strength test, the specimens were cut with the dimension of $76 \times 25 \times 3 \mathrm{~mm}$; crosshead motion rate was $2.8 \mathrm{~mm} \cdot \mathrm{min}^{-1}$.

\subsection{Chemical Stability}

The analysis of Table 3 shows that the ions are weakly released in an acidic, basic and neutral medium. This low rate of salting out is observed due to the low variation of the conductivity of the tempering solution. But we note that after 8 days this value no longer changes. This reflects good chemical stability of ceramics in an acidic and basic medium.

\section{Results and Discussion}

\subsection{Thermal Analysis of Coffee Fiber Hull}

The ATG-DTG curves of the coffee hulls are shown in Figure 3. Thermogravimetric analysis (ATG) (in red) provides the loss of mass of the material during thermal degradation. The heat treatment phenomenon is described by [19]. The second derivative of thermogravimetric analysis (DTG) (in blue) gives the degradation temperatures of the hulls as defined by [19].

Observation of the curve shows that around $440^{\circ} \mathrm{C}$, the biomass has been completely consumed Figure 1 shows four main phases of mass loss. The first

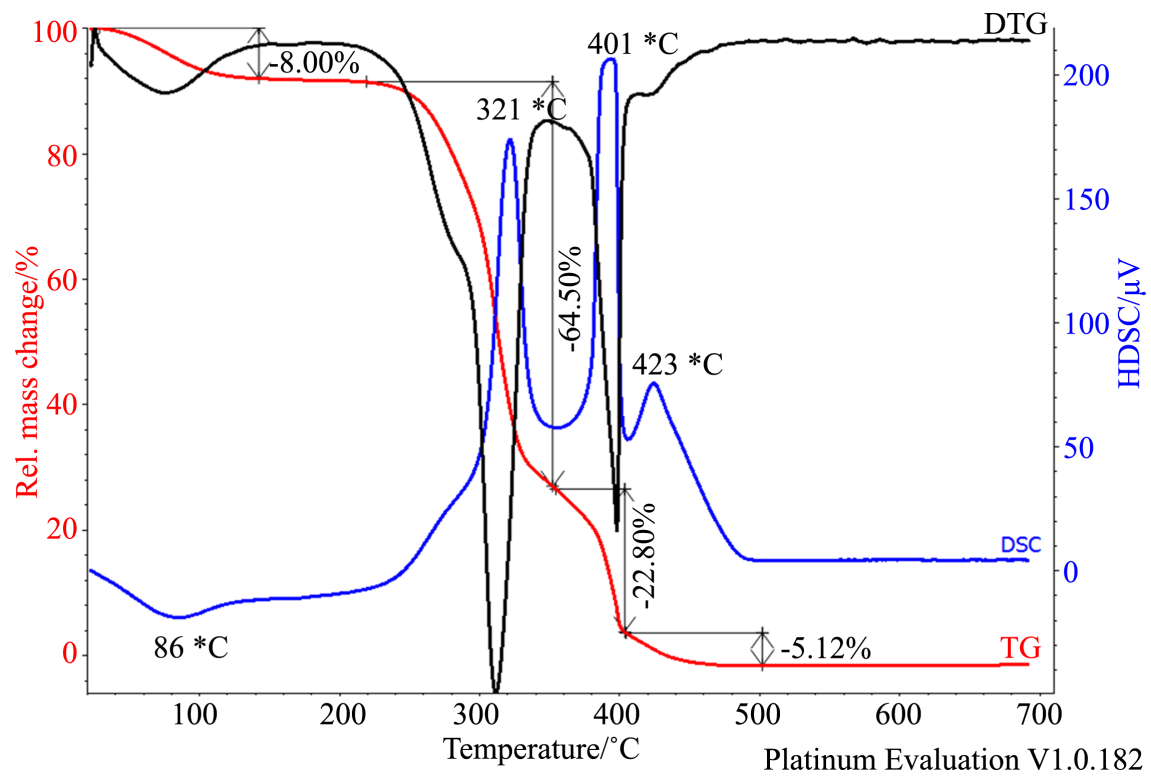

Figure 1. Thermogravimetric and differential scanning calorimetry of raw coffee hulls. 
mass loss of $8.00 \%$ by weight is located between 40 to $100^{\circ} \mathrm{C}$ and has a peak around $86^{\circ} \mathrm{C}$; it corresponds to the evaporation of the water present in the hulls. The second loss of mass correspond to mass loss of $64.50 \%$ is observed between $300^{\circ} \mathrm{C}$ and $400^{\circ} \mathrm{C}$, with a DTG maximum at $321^{\circ} \mathrm{C}$, It is assigned to the degradation of polysaccharides (hemicelluloses and cellulose) in the fiber of coffee hulls [20]. The third loss of $22.60 \%$ observed between $321^{\circ} \mathrm{C}$ and $401^{\circ} \mathrm{C}$ would be due to the degradation of cellulose; in fact, cellulose would degrade around $401^{\circ} \mathrm{C}$. Between $401^{\circ} \mathrm{C}$ and $423^{\circ} \mathrm{C}$, a loss of $5.12 \%$ is observed having a peak around $423^{\circ} \mathrm{C}$, which would be due to the degradation of the lignin at $423^{\circ} \mathrm{C}$ [20]. We note that these results are in agreement with the chemical composition of coffee hulls: the major constituents of which are cellulose, hemicellulose and lignin; they degrade with a strong loss of mass [21]. In addition, hemicelluloses decompose at low temperatures because their molecular chains are short. In addition to their low molecular mass, they have fewer regular structures in their chains [21].

The curve of Figure 1 shows four thermal phenomena for coffee hulls. One endothermic (Table 1) peak was observed at a lower temperature around $86^{\circ} \mathrm{C}$ and three exothermic peaks range between $321^{\circ} \mathrm{C}, 401^{\circ} \mathrm{C}$ and $423^{\circ} \mathrm{C}$. The first thermal incident was attributed to evaporation of water molecules from fibers, the second, third and fourth respectively represent the degradation of holocelluloses, celluloses and lignin from the coffee hulls [21].

\subsection{Infrared Fourier Transform Analysis Coffee Fiber Hull}

Figure 2, FT-IR analysis of coffee hulls shows different peak intensities.

The large peak intensity at $3299 \mathrm{~cm}^{-1}$ can be attributed to O-H stretching group of alcohol (cellulose content in coffee pulp). The intensity $2926 \mathrm{~cm}^{-1}$ can be attributed to $\mathrm{C}-\mathrm{H}$ stretching group of alkanes or the vibration of methoxy group of lignin. The intensity peak between $1300-1150 \mathrm{~cm}^{-1}$ and those of $1238-$ $1016 \mathrm{~cm}^{-1}$ could be attributed to C-O stretch of alcohols, esters or ethers. These results are in agreement with data found in the literature concerning coffee pulp. The study indicates that coffee skin can be an interesting filler for polymeric composites; its properties can be ameliorated by pretreatments techniques.

\subsection{Morphological Investigation (SEM) of Coffee Fiber Hull}

Figure 3(a) shows that the neat coffee hulls exhibit a rough surface due to the

Table 1. Types of thermal phenomena.

\begin{tabular}{ccccc}
\hline & $\begin{array}{c}\text { Temperature } \\
\left({ }^{\circ} \mathrm{C}\right)\end{array}$ & $\begin{array}{c}\text { Partial loss } \\
\text { of mass }(\%)\end{array}$ & $\begin{array}{c}\text { Total loss of } \\
\text { mass }(\%)\end{array}$ & $\begin{array}{c}\text { Type of } \\
\text { reaction }\end{array}$ \\
\hline $\begin{array}{c}\text { Pulp of } \\
\text { coffee } \\
\text { hulls }\end{array}$ & 36 & 8 & & Endothermic \\
& 401 & 64.50 & 100 & Exothermic \\
& 423 & 22.8 & & Exothermic \\
\hline
\end{tabular}




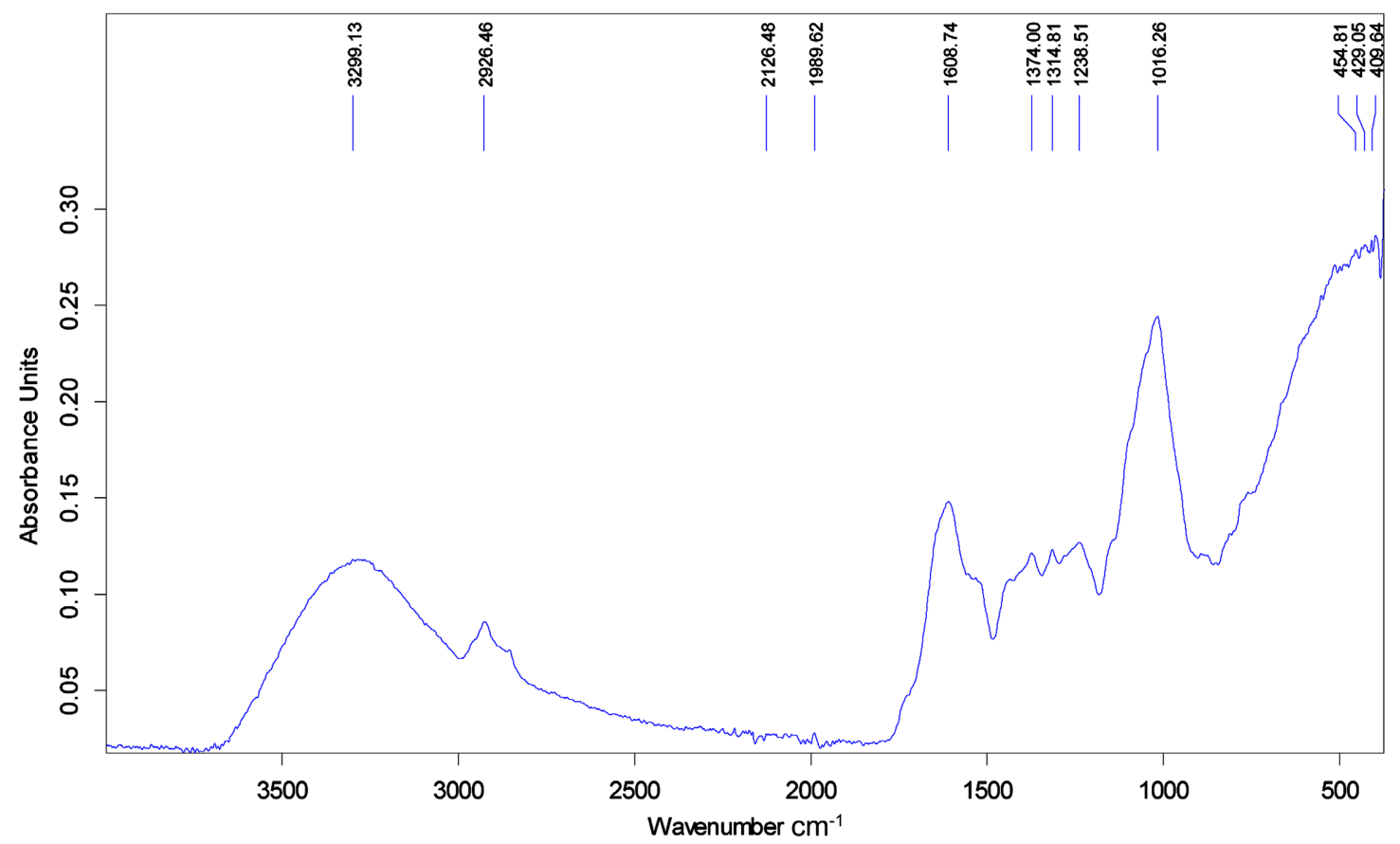

Figure 2. Infrared of raw coffee shell pulp.

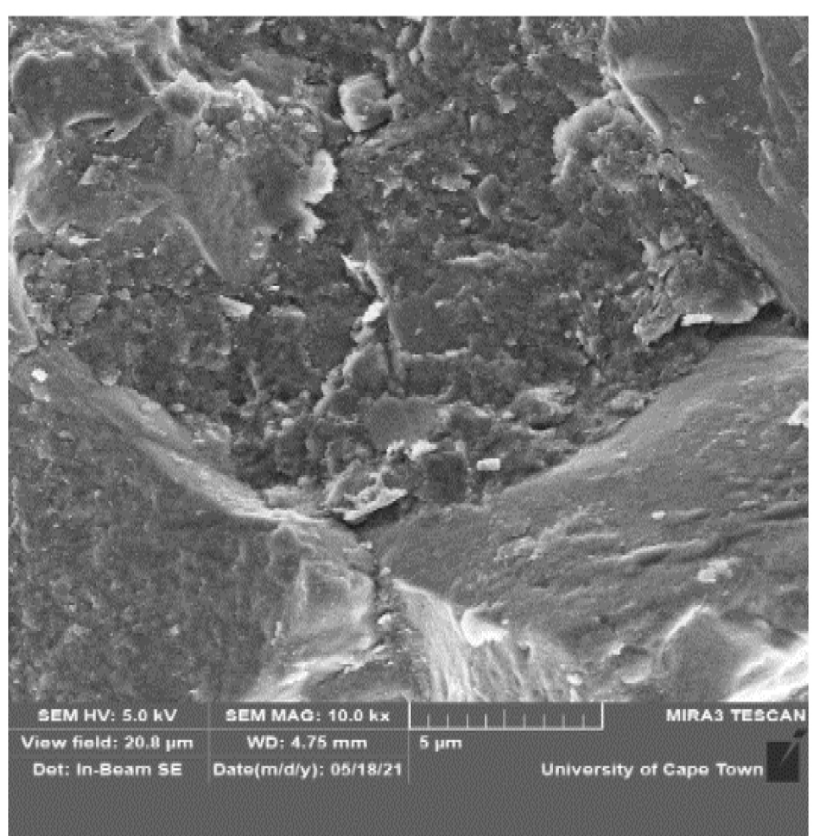

(a)

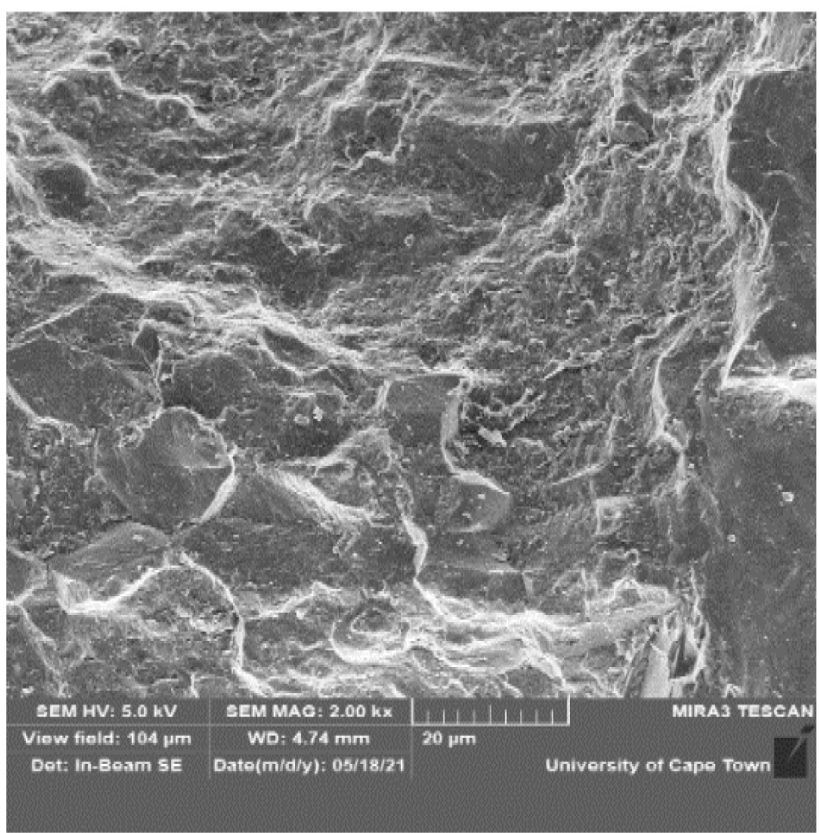

(b)

Figure 3. Scanning electron micrographs of coffee hulls (a) (untreated or, neat coffee skin); (b) (mercerized coffee skin).

presence of non-cellulosic materials, while figure (b) shows mercerized fibers that were made to react with caustic soda; In this image (b) gaps between the fibers can be clearly observed, which indicate the partial removal of lignin and hemicellulose. Also, this can be related to mechanical properties enhancement that can be observed in the composites after addition of treated coffee pulp. 


\subsection{Physico-Chemical Composition of Coffee Hulls}

The results are given in Table 2 below.

The coffee hulls studied has a dry matter content of $88.1 \%$ and an organic matter content of $92.1 \%$. This high organic matter content shows that coffee hulls can be an important source of nutrients for microorganisms in anaerobic digestion, this can explain why it's used as fertilizer. These results are close to those of [19] On the other hand, these values are slightly higher than those of [20] which had $85.9 \%$ for dry matter and $87.7 \%$ for organic matter. In addition, [21] had high values, i.e. a dry matter content of $91.5 \%$ and $93.3 \%$ for organic matter. As regards the lignocellulosic composition, there are $40.1 \%$ crude fibers, $35.3 \%$ lignin and $41.4 \%$ cellulose. These results are in line with those of [18] who for these same compounds had $42.22 \%, 38 \%$ and $43.13 \%$ respectively. In addition, these contents are higher than that of [21] whose work revealed a crude fiber content of $36.6 \%$ against $21.4 \%$ of lignin. Such lignin (between $10 \%$ and $35 \%$ ) and cellulose (between $20 \%$ and 50\%) contents immediately make coffee shells lignocellulosic biomass according to [22]. All these results demonstrate the variability in the composition of coffee shells. This can be explained by differences in the soil composition of the place of origin, the difference in the degree of maturity as well as the harvest period. But the fact remains that coffee hulls constitute a promising source of fibers that can be used as reinforcement or filler.

\section{Density}

Density is an important parameter for plastic composites in view of weight reduction. The average value obtained in the case of apparent density of coffee hulls powder is $\rho_{v}=0.940 \pm 0.002 \mathrm{~g} / \mathrm{cm}^{3}$.

This density can be compared to the density of plant fibers such as oil palm fiber.

The average value obtained in the case of wet density is $\rho_{m}=0.789 \pm 0.003$ $\mathrm{g} / \mathrm{cm}^{3}$. This value compares to the density values of some plant fibers used to

Table 2. Chemical composition of coffee hulls.

\begin{tabular}{cc} 
Constituents & Before pretreatment \\
\hline Dry matter content $\left(\mathrm{g} / 100^{\star} \mathrm{g}\right)$ & $88.1 \pm 0.1$ \\
Water content $\left(\mathrm{g} / 100^{*} \mathrm{~g}\right)$ & $11.9 \pm 0.1$ \\
Organic matter content $\left(\mathrm{g} / 100^{+} \mathrm{g}\right)$ & $92.1 \pm 0.2$ \\
Ash content $\left(\mathrm{g} / 100^{+} \mathrm{g}\right)$ & $7.9 \pm 0.2$ \\
Reducing sugar content $\left(\mathrm{g} / 100^{\star} \mathrm{g}\right)$ & $0.020 \pm 0.003$ \\
Crude fiber content $\left(\mathrm{g} / 100^{+} \mathrm{g}\right)$ & $40.1 \pm 1.2$ \\
Lignin content $\left(\mathrm{g} / 100^{+} \mathrm{g}\right)$ & $35.3 \pm 1.8$ \\
Cellulose content $\left(\mathrm{g} / 100^{+} \mathrm{g}\right)$ & $41.4 \pm 0.3$
\end{tabular}

+Dry base, ${ }^{\star}$ Wet base. 
reinforced polymer such as kenaf fibers $\left(0.6-1.5 \mathrm{~g} / \mathrm{cm}^{3}\right)$, Oil palm fiber $(0.7-1.6$ $\left.\mathrm{g} / \mathrm{cm}^{3}\right)$ or sisal $\left(1.2 \mathrm{~g} / \mathrm{cm}^{3}\right)$ shows that composites obtained after processing will be light [23].

\subsection{Thermal, Morphology, Mechanical and Physicochemical Stability of Composite (Coffee Fiber/LLDPE)}

\subsubsection{Thermogravimetric Analysis of Composite Coffee Fiber/LLDPE}

Thermogravimetric analysis (TGA) was used to investigate the effect of cellulose fibers on the thermal stability of the composites. In the obtained LLDPE thermograms three main weight loss regions can be observed. All the samples show an initial weight loss in the region $75^{\circ} \mathrm{C}-150^{\circ} \mathrm{C}$ caused by the evaporation of water. Between 2.5 and $3.5 \mathrm{wt} \%$ physically and chemically bound water was detected in neat LLDPE and LLDPE composites thermograms. The second degradation region is located between $220^{\circ} \mathrm{C}$ and $300^{\circ} \mathrm{C}$ and is due to the pyrolysis of cellulose fibers and the second stage of degradation mainly involves dehydration reactions and the formation of volatile products.

The third stage weight loss occurs above $337^{\circ} \mathrm{C}$ and consists of decomposition of carbonaceous matter. For LLDPE composites as regard to neat LLDPE, showing a marginal increase of the thermal stability caused by the cellulose fibers. Lee showed that the thermal stability of LLDPE composites was improved with the increase of the CSP loading.

\subsubsection{Morphological Investigation Composite Coffee Fiber/LLDPE}

The morphology of the mercerized coffee fiber is shown in Figure 4(a) and Figure 4(b) while the morphology of the untreated coffee fiber shown in Figure 1 (c) is naturally rough while Figure 4 (a) and Figure 4(b) show a uniform surface texture which can be attributed to a significant amount of MAPE deposited on the fabric surface. The MAPE deposited on the fiber surface is believed to have penetrated the fiber porosity and chemically grafted with the mercerized fiber as a result of the solution treatment performed. With the MAPE addition, gaps between natural fibers and LLDPE were significantly reduced, and as a consequence, an improvement over the interface for the composite can be appreciated. This result confirms that MAPE addition improved the interfacial property of the hydrophobic LLDPE matrix and the hydrophilic natural fibers.

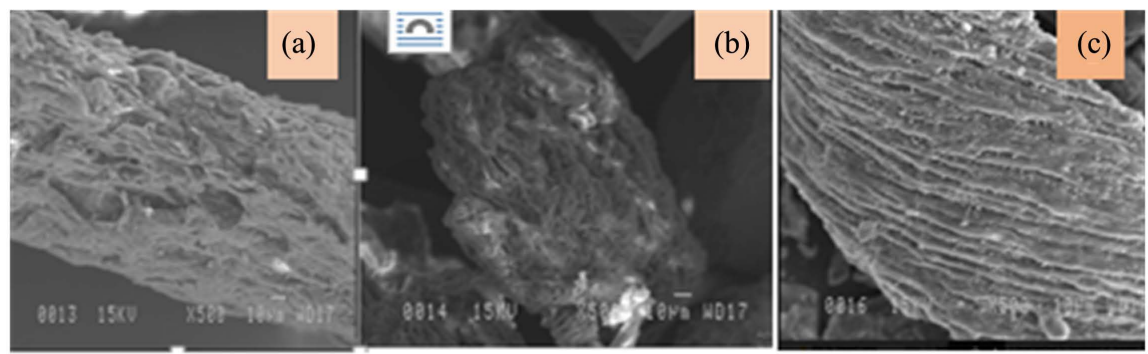

Figure 4. SEM images showing Morphology of the mercerized ((a) and (b)) and untreated (c) coffee husk fiber. 
Also, this can be related to mechanical properties enhancement observed in the composites after the MAPE addition.

\subsubsection{Mechanical Properties}

The curves representing load against Tensile Strength are represented in Table 3(a)-(c) below.

The tinsel stain/stress profiles for tested samples of LLDPE/untreated coffee husk at; 15\%, 30\% and 45\% (Table 3(a)) fiber loading are shown in Figure 4(a). The results reveal that the specimens ( 1 to 5 ) from the same sample (all \% fiber loadings alike), have different tensile stain/stress profiles which is an indication that different portions of the same sample had variation in mechanical properties. The Mechanical properties; mean tensile stress and mean tensile stain decreased while mean modulus (automatic Young's) increased as the fiber dosage in the composite increased from $15 \%$ through $30 \%$ to $45 \%$. These observations could be attributed to the strong surface attraction between the coffee fiber and the LLDPE particles in the matrix making it extremely difficult to ensure uniform

Table 3. (a) Tinsel stain/stress profiles for tested samples of LLDPE/untreated coffee husk at; $15 \%, 30 \%$ and $45 \%$ fiber loading and Mechanical properties; (b) Tinsel stain/stress profiles for tested samples of LLDPE/MAPE/untreated coffee husk at; $30 \%$ and $45 \%$ fiber loading and Mechanical properties; (c) Mercerized fiber/MAPE composite at all loadings $(15 \%, 30 \%$, and $45 \%)$ of fiber composites and Mechanical properties.

(a)

\begin{tabular}{cccc}
\hline & LLDPE/15\% C & LLDPE/30\% C & LLDPE/45\% C \\
\hline Mean tensile stress & 12.887 & 8.789 & 6.273 \\
Mean tensile strain & 16.796 & 9.864 & 5.843 \\
Mean Energy at Break & 0.354 & 0.165 & 0.061 \\
Mean Modulus (automatic young) in MPa & 222.01277 & 239.99417 & 284.16899 \\
\hline
\end{tabular}

(b)

\begin{tabular}{ccc}
\hline & LLDPE/30\% C/MAPE & LLDPE/45\% C/MAPE \\
\hline Mean tensile stress & 8.865 & 8.583 \\
Mean tensile strain & 9.079 & 6.333 \\
Mean Energy at Break & 0.131 & 0.075 \\
Mean Modulus (automatic young) in MPa & 239.49223 & 256.51829 \\
\hline
\end{tabular}

(c)

\begin{tabular}{cccc}
\hline & $\begin{array}{c}\text { LLDPE/15\% C/ } \\
\text { NaOH/MAPE }\end{array}$ & $\begin{array}{c}\text { LLDPE/30\% C/ } \\
\text { NaOH/MAPE }\end{array}$ & $\begin{array}{c}\text { LLDPE/45\% C/ } \\
\text { NaOH/MAPE }\end{array}$ \\
\hline Mean tensile stress & 11.106 & 7.602 & 5.448 \\
Mean tensile strain & 13.836 & 7.399 & 4.250 \\
Mean Energy at Break & 0.276 & 0.119 & 0.058 \\
$\begin{array}{c}\text { Mean Modulus } \\
\text { (automatic young) in MPa }\end{array}$ & 219.94115 & 189.75296 & 278.94554 \\
\hline
\end{tabular}


dispersion within the composite. This observation can be termed a dispersion problem and it increased with increase in the fiber fraction in the composited matrix (the individual specimen profiles deviate further). This phenomenon could lead to formation of defect sites in the composite.

The cases where the coupling agent MAPE was used on untreated fiber loading of $30 \%$ and $45 \%$ are presented in Table $3(\mathrm{~b})$. The profile of the specimen at $45 \%$ was relatively closer, smooth, thus the fracture process was also relatively gentler indicative of the fact that the tougher LLDPE plays a major role and suggests that the major mechanical strength of the composite came from the LLDPE matrix. This was accompanied by uniform changes in mechanical properties; the tensile strength at yield decreased while the Modulus increased as the fiber loading increased (From 30\% to 45\%) in the composite. On the other hand, in the specimens or samples at $30 \%$ dosage, the profiles relatively dropped suddenly indicating the sudden separation of the coffee fiber and LLDPE matrix interface, and failure or sudden break of the coffee fiber. The coffee husk which were in the form of short fiber or powder, and whose specific ratio might have been so small with a length shorter than critical would have pulled out (coffee fiber fail to fully exert the fiber strength with the critical length and unable to play a reinforcing role but rather serve as filling material). MAPE as macromolecular coupling agents has improved the interfacial adhesion of LLPDE matrix and Coffee husk fibers and solved the poor compatibility of natural fiber and LLPDE matrix at the $45 \%$ fiber loading ensuring proper dispersion free from agglomerations. The maleic anhydride groups of MAPE react with the hydroxyl groups $(\mathrm{OH})$ of maple fibers thus creating strong bonds between the two materials [24]. These results are indicative of the fact that both mercerization and MAPE (coupling agent) have significant positive effects on the fiber-matrix interaction in terms of adhesion, wetting and dispersion.

The profiles for mercerized fiber/MAPE composite at all loadings (15\%, 30\%, and $45 \%$ ) of fiber composites are shown in Table $3(\mathrm{c})$. The profiles for mercerized fiber/MAPE were generally gentle, close to one another and smooth. The gentility and smoothness of the individual specimens per sample improved from $15 \%$ to $30 \%$ fiber loading but deviated at $45 \%$ loading. The mechanical properties; tensile strength and modulus both decreased as the fiber fraction increased from $15 \%$ to $30 \%$ but the trend changes as the modulus instead increased as the fiber fraction increased from $30 \%$ to $45 \%$. Jayaraman et al. [25] prepared composites of linear medium density polyethylene (LMDPE) with sisal and wood fibers via rotational molding using different amounts of fibers $(5 \%-25 \%)$ and obtained similar results. The treatment produced a better fiber distribution and consequently a more uniform composite morphology without voids and gaps between the fibers and the matrix, allowing the possibility to use higher fiber contents (up to $30 \% \mathrm{wt}$.) with acceptable mechanical properties.

Chemical treatment especially using sodium hydroxide (Alkali treatment of natural fibers, also called mercerization), leads to fibrillation which causes the breaking down of the composite fiber bundle into smaller fibers. Mercerization 
reduces fiber diameter, thereby increasing the aspect ratio which leads to the development of a rough surface topography that consequently enhances the fiber-matrix interface adhesion resulting in better mechanical properties [26]. Moreover, mercerization increases the number of possible reactive sites and allows better fiber wetting. It also has an effect on the chemical composition of the flax fibers, degree of polymerization, and molecular orientation of the cellulose crystallites due to the loss of cementing substances like lignin and hemicellulose which were removed during the mercerization process. Surface treatment and use of coupling agent led to better fiber distribution and a more uniform composite morphology allowing the possibility to use higher fiber contents in rotational molding. However, there is a limited amount of fiber that can be added to produce good composite materials, in this case, fiber contents of up to $30 \%$ can be used since higher fiber content can lead to agglomerations and porosity limiting stress transfer and promoting crack. At low fiber contents (15\% wt.), the mechanical properties were improved using treated fiber composites (TFC) compared to untreated fiber composites (UFC) and Similar results were reported in the literature [27].

\subsubsection{Water Absorption Test (\%) and Apparent Porosity (\%) of Composites Materials}

The percentage water absorption of coffee hulls fibers reinforced LLDPE composites is shown in Table 4. The water sorption experiments have been carried out for 24 hours at environment temperature.

The percentage of water absorption is found to be increased with increasing fiber content in all cases. The composite: $45 \%$ untreated coffee hulls/LLDPE shows higher water absorption. The increasing water absorption is due to the hydrophilic nature of coffee hulls fiber and greater interfacial area between fiber and matrix. The moisture absorption by LLDPE is almost negligible due to its hydrophobic nature. The fiber surface modification by chemical treatments significantly improves the fiber matrix adhesion, which in turn reduce water sorption and improves the mechanical properties of composite.

\subsubsection{Chemical Stability}

The analysis of Table 5 shows that the ions are weakly released in an acidic,

Table 4. Percentage water absorption of coffee hulls fiber/LLDPE composites.

\begin{tabular}{ccccccc}
\hline \multirow{2}{*}{$\begin{array}{c}\text { Coffee } \\
\text { hulls } \\
(\%)\end{array}$} & \multicolumn{2}{c}{$\begin{array}{c}\text { LLDPE/untreated } \\
\text { coffee hulls fiber }\end{array}$} & $\begin{array}{c}\text { Water } \\
\text { absorption } \\
(\%)\end{array}$ & $\begin{array}{c}\text { Porosity } \\
(\%)\end{array}$ & $\begin{array}{c}\text { LLPPE/MAPE/untreated } \\
\text { coffee hulls fiber }\end{array}$ & \multicolumn{2}{c}{$\begin{array}{c}\text { LLDPE/MAPE/mercerized } \\
\text { absoffion } \\
\text { coffee hulls fiber }\end{array}$} \\
\cline { 3 - 7 } & $\begin{array}{c}\text { Porosity } \\
(\%)\end{array}$ & $\begin{array}{c}\text { Water } \\
\text { absorption } \\
(\%)\end{array}$ & $\begin{array}{c}\text { Porosity } \\
(\%)\end{array}$ \\
\hline 15 & $15.04 \pm 2.12$ & $24.01 \pm 2.45$ & $11.09 \pm 2.14$ & $17.06 \pm 1.32$ & $8.02 \pm 1.32$ & $12.23 \pm 2.11$ \\
30 & $19.23 \pm 1.76$ & $30.56 \pm 1.65$ & $14.16 \pm 1.23$ & $22,64 \pm 0.67$ & $11.19 \pm 3.32$ & $17.6 \pm 2.45$ \\
45 & $32.13 \pm 3.01$ & $51.46 \pm 1.12$ & $26.10 \pm 3.34$ & $41,6 \pm 4.98$ & $20.33 \pm 4.32$ & $32.09 \pm 4.57$ \\
\hline
\end{tabular}


Table 5. Influence of conductivity at given $\mathrm{PH}$ in function of soaking time.

\begin{tabular}{|c|c|c|c|c|c|c|c|}
\hline Day & 1 & 2 & 4 & 6 & 8 & 10 & 30 \\
\hline \multicolumn{8}{|c|}{ Cond $(\mu \mathrm{S} / \mathrm{cm})$ at } \\
\hline & \multicolumn{7}{|c|}{ PH 3.98} \\
\hline $15 \%$ & 150 & 157 & 159 & 157 & 155 & 155 & 155 \\
\hline $30 \%$ & 150 & 143 & 153 & 152 & 152 & 152 & 152 \\
\hline \multirow[t]{2}{*}{$45 \%$} & 150 & 150 & 150 & 152 & 152 & 152 & 152 \\
\hline & \multicolumn{7}{|c|}{ PH 6.74} \\
\hline $15 \%$ & 5 & 5.1 & 5.3 & 5.3 & 5.6 & 6.07 & 6.67 \\
\hline $30 \%$ & 5 & 5.01 & 5.21 & 5.41 & 5.79 & 5.81 & 5.81 \\
\hline \multirow[t]{2}{*}{$45 \%$} & 5 & 5.03 & 5.09 & 5.13 & 5.17 & 5.22 & 5.23 \\
\hline & \multicolumn{7}{|c|}{ PH 9.05} \\
\hline $15 \%$ & 1000 & 1003 & 1013 & 1008 & 1007 & 1007 & 1008 \\
\hline $30 \%$ & 1000 & 1000 & 1001 & 1001 & 1002 & 1002 & 1008 \\
\hline $45 \%$ & 1000 & 1043 & 1057 & 1023 & 1012 & 1007 & 1007 \\
\hline
\end{tabular}

basic and neutral medium. This low rate of salting out is observed due to the low variation of the conductivity of the tempering solution. But we note that after 8 days this value no longer changes. This reflects good chemical stability of composite in an acidic and basic medium. The mechanical properties confirm the resistance to degradation in an acid-base medium.

\section{Conclusion}

The properties of coffee hulls fiber-based LLDPE composites, in general, are dependent on coffee hulls fiber percentage, as well as the addition of a coupling agent to ensure better interaction between coffee hulls fiber and matrix. The addition of coffee hulls fiber produces an environmentally friendly material without loss of the desired characteristics of the virgin LLDPE. It is clear that coffee hulls fiber has great potential as a filler and reinforcement for composites requiring similar properties to LLDPE. In the present research effort, mechanical, thermal, morphology and water absorption properties of coffee hull fibers/ LLDPE composites are conducted and the following conclusions can be drawn: Mechanical properties of LLDPE are increased by reinforcement of coffee hull fibers up to $30 \% \mathrm{wt}$. and then decreased. The statistical analysis shows that all the composite samples are significant. Based on experimental results, this study has led to the following conclusions: The coffee hull fibers can successfully be used as a reinforcing agent to fabricate composite. The fiber surface modification by chemical treatments significantly improves the fiber-matrix adhesion, which in turn improves the mechanical properties of the composite. Water absorption property is found to increase on increasing the fiber contents in composites. The prepared composite can be regarded as lightweight and low manu- 
facturing cost engineering materials for industrial applications. As a perspective, it will be desirable to study the influence of pressure and temperature on the physicomechanical properties

\section{Acknowledgements}

The authors acknowledge the Research Unit for Macromolecular Chemistry, Applied Inorganic Chemistry Laboratory, Faculty of Science, University of Yaounde I, Yaounde, Cameroon for the technical support.

\section{Conflicts of Interest}

The authors of this manuscript declare that do not hold any conflicts of interest that might have any bearing on research reported in their submitted manuscript.

\section{References}

[1] Carbonell-Verdú, A., García-García, D., Jordá, A., Samper, M.D. and Balart, R. (2015) Development of Slate Fiber Reinforced High Density Polyethylene Composites for Injection Molding. Composites Part B: Engineering, 69, 460-466. https://doi.org/10.1016/j.compositesb.2014.10.026

[2] Dominici, F., García, D.G., Fombuena, V., Luzi, F., Puglia, D., Torre, L. and Balart, R. (2019) Bio-Polyethylene-Based Composites Reinforced with Alkali and Palmitoyl Chloride-Treated Coffee Silver Skin. Molecules, 24, 3113. https://doi.org/10.3390/molecules24173113

[3] Zhang, H. (2014) Effect of a Novel Coupling Agent, Alkyl Ketene Dimer, on the Mechanical Properties of Wood-Plastic Composites. Materials \& Design, 59, 130-134. https://doi.org/10.1016/j.matdes.2014.02.048

[4] Garcia-Garcia, D., Carbonell-Verdu, A., Jordá-Vilaplana, A., Balart, R. and Garcia-Sanoguera, D. (2016) Development and Characterization of Green Composites from Bio-Based Polyethylene and Peanut Shell. Journal of Applied Polymer Science, 133, 1-12. https://doi.org/10.1002/app.43940

[5] Das, O., Sarmah, A.K. and Bhattacharyya, D. (2015) A Sustainable and Resilient Approach through Biochar Addition in Wood Polymer Composites. Science of the Total Environment, 512, 326-336. https://doi.org/10.1016/j.scitotenv.2015.01.063

[6] Bayer, J., Granda, L.A., Méndez, J.A., Pèlach, M.A., Vilaseca, F. and Mutijé, P. (2017) Cellulose Polymer Composites (WPC). In: Deans, M., Ed., Advanced High Strength Natural Fibre Composites in Construction, Elsevier, Berkeley, 115-139. https://doi.org/10.1016/B978-0-08-100411-1.00005-4

[7] Spear, M., Eder, A. and Carus, M. (2015) Wood Polymer Composites. In: Ansell, M., Ed., Wood Composites, Elsevier, Berkeley, 195-249. https://doi.org/10.1016/B978-1-78242-454-3.00010-X

[8] Saba, N., Paridah, M. and Jawaid, M. (2015) Mechanical Properties of Kenaf Fibre Reinforced Polymer Composite: A Review. Construction and Building Materials, 76, 87-96. https://doi.org/10.1016/j.conbuildmat.2014.11.043

[9] Quiles-Carrillo, L., Montanes, N., Garcia-Garcia., D., Carbonell-Verdu, A., Balart, R. and Torres-Giner, S. (2018) Effect of Different Compatibilizers on InjectionMolded Green Composite Pieces Based on Polylactide Filled with Almond Shell Flour. Composites Part B: Engineering, 147, 76-85. https://doi.org/10.1016/j.compositesb.2018.04.017 
[10] Chan, C.M., Vandi, L.J., Pratt, S., Halley, P., Richardson, D., Werker, A. and Laycock, B. (2018) Mechanical Properties of Poly(3-hydroxybutyrate-co-3-hydroxyvalerate)/ Wood Flour Composites: Effect of Interface Modifiers. Journal of Applied Polymer Science, 135, 46828. https://doi.org/10.1002/app.46828

[11] Echeverria, M.C. and Nuti, M. (2017) Valorization of the Residues of Coffee AgroIndustry: Perspectives and Limitations M.C. The Open Waste Management Journal, 10, 13-22. https://doi.org/10.2174/1876400201710010013

[12] Hahladakis, J.N., Velis, C.A., Weber, R., Iacovidou, E. and Purnell, P. (2018) An Overview of Chemical Additives Present in Plastics: Migration, Release, Fate and Environmental Impact during Their Use, Disposal and Recycling. Journal of Hazardous Materials, 344, 179-199. https://doi.org/10.1016/j.jhazmat.2017.10.014

[13] Bachmann, N., Deront, M., Fruteau, H., Holliger, C., Membrez, Y. and Wellinger, A. (2011) Optimisation des tests standardisés de digestibilité dans des réacteurs batch. Office fédéral de l'énergie OFEN Programme de recherche énergétique, Berne, Laboratoire de Biotechnologie Environnemental (LBE), 1015 Lausanne.

[14] Wolff, J.P. (1968) Méthodes d'analyse des corps gras. Azoulay, Paris.

[15] Monties, B. (1984) Dosage de la lignine insoluble en milieu acide: Influence du préraitement par hydrolyse acide sur la lignine Klason de bois et de pailleAgronomie. EDP Sciences, 4, 387-392. https://doi.org/10.1051/agro:19840410

[16] Ernesto de la Torre, C. (2015) Préparation de charbon actif à partir de coques de noix de palmier à huile pour la récupération d'or et le traitement d'effluents cyanurés. Thèse, Université Catholique de Louvain, $350 \mathrm{p}$.

[17] Dias, O.A.T., Negrão, D.R., Silva, R.C., Funari, C.S., Cesarino, I. and Leao, A.L. (2016) Studies of Lignin as Reinforcement for Plastics Composites. Molecular Crystals and Liquid Crystals, 628, 72-78. https://doi.org/10.1080/15421406.2015.1137677

[18] ASTM-C373 (1999) American Standard and Testing Materials, C373-88 (ASTM). Standard Test Method for Water Absorption, Bulk Density, Apparent, Porosity, and Apparent Specific Gravity of Fired Whiteware Products.

[19] Manimaran, P., Kumar, C., Bharanirajan, R. and Premnauth, I. (2016) Investigations on Mechanical Properties of Al 8011 Reinforced with Micro B4C/Red Mud by Stir Casting Method. Materials Science.

[20] Djomi, R., Meva'a, L.J.R., Nganhou, J., Mbobda, G., Njom, A.E., Bampel, Y.D.M. and Tchinda, J.-B.S. (2018) Physicochemical and Thermal Characterization of Dura Palm Kernel Powder as a Load for Polymers: Case of Polyvinyl Chloride. Journal of Materials Science and Chemical Engineering, 6, 1-18.

https://doi.org/10.4236/msce.2018.66001

[21] Samomssa, I., Nono, Y.J., Tsamo, C., Dinica, M.R. and Kamga, R. (2019) Influence of Physico-Chemical Parameters on Fuel Briquettes Properties Formulated with Mixture of Biomasses. Journal of Environmental Science and Pollution Research, 5, 338-341. https://doi.org/10.30799/jespr.165.19050202

[22] Bai, Y.Y., Xiao, L.P., Shi, Z.J. and Sun, R.C. (2013) Structural Variation of Bamboo Lignin before and after Ethanol Organosolv Pretreatment. International Journal of Molecular Sciences, 14, 21394-21413. https://doi.org/10.3390/ijms141121394

[23] Balakrishnan, P., John, M.J., Pothen, L., Sreekala, M.S. and Thomas, S. (2016) Natural Fibre and Polymer Matrix Composites and Their Applications in Aerospace Engineering. In: Advanced Composite Materials for Aerospace Engineering, Woodhead Publishing, Cambridge, 365-383.

https://doi.org/10.1016/B978-0-08-100037-3.00012-2 
[24] Mohanty, S., Verma, S.K. and Nayak, S.K. (2006) Dynamic Mechanical and Thermal Properties of MAPE Treated Jute/HDPE Composites. Composites Science and Technology, 66, 538-547. https://doi.org/10.1016/j.compscitech.2005.06.014

[25] Jayaraman, K., Lin, R., Bose, D., et al. (2007) Natural Fibre-Reinforced Thermoplastics Processed by Rotational Moulding. Advanced Materials Research, 29-30, 307. https://doi.org/10.4028/www.scientific.net/AMR.29-30.307

[26] Joseph, K., Mattoso, L.H.C., Toledo, R.D., et al. (2000) Natural Fiber Reinforced Thermoplastic Composites. In: Frollini, E., Leao, A.L. and Mattoso, L.H.C., Eds., Natural Polymers and Agrofibers Composites, Embrapa, San Carlos, Chapter 4, 159-201.

[27] Cisneros-López, E.O., González-López, M.E., Pérez-Fonseca, A.A., González-Núñez, R., Rodrigue, D. and Robledo-Ortíz, J.R. (2016) Effect of Fiber Content and Surface Treatment on the Mechanical Properties of Natural Fiber Composites Produced by Rotomolding. Composite Interfaces, 24, 35-53.

https://doi.org/10.1080/09276440.2016.1184556 